\title{
Analisis Penggunaan Media Sosial Dan Sumber Belajar Digital Dalam Pembelajaran Bagi Siswa Digital Native Di SMAN 2 Painan
}

\author{
Sona Rahmada Yani ${ }^{1}$, Menik Kurnia Siwi ${ }^{2}$ \\ ${ }^{1,2}$ Economic Education Program, Padang State University, Sumatera Barat, Indonesia \\ sona.rahmadayani.98@gmail.com,menikkurnia@gmail.com,
}

\begin{abstract}
The purpose of this study is to find the effect of the use of social media and digital learning resources fordigital native in learning. Type of this research is associative descriptive. Descriptive research is research that describes or explains something of the relationships and influences between variables as they are. While associative research is research looking for relationships between a variable with other variables. The population of this study was Class XI IPS 1, XI IPS 2 and XI IPS 3 in SMAN 2 Painan. The sample used in this study was obtained by total sampling of 97 people. Based on the results of research and discussion on the use of social media it can be concluded that the use of social media by digital native students at SMAN 2 Painan can be classified as quite high. And the use of digital learning resources by native digital students can be classified as quite high. This means that digital learning resources have a positive impact if used continuously in learning.
\end{abstract}

Keywords: Use of Social Media, digital learning resources

History of Article:

Received : (01-11-2019),

Accepted : (20-11-2019),

Publised : (24-03-2020)

\section{Citation:}

Yani, S.R \&Siwi, M.S (2020) Analisis Penggunaan Media Sosial Dan Sumber Belajar Digital Dalam Pembelajaran Bagi Siswa Digital Native Di SMAN 2 Painan. Jurnal Pendidikan Ekonomi, 13(1), 01-07

(C) Universitas Negeri Malang 


\section{PENDAHULUAN}

Pendidikan merupakan sesuatu yang sangat penting bagi kehidupan manusia, karena pendidikan bisa mempengaruhi kualitas kehidupan manusia. Apalagi saat ini perkembangan teknologi terjadi sangat cepat, sehingga memaksa kita semua harus bisa mengikuti perkembangan zaman jika tidak ingin menjadi orang yang tertinggal. Sejak dimasuki era digital, masyarakat menemukan "suatu cara baru" di dalam berkomunikasi dan berinteraksi satu sama lain. Teknologi memberikan kemudahan yang berlimpah dalam mencari informasi yang mereka butuhkan. Mereka saling terhubung satu sama lain baik dalam berkomunikasi, berperilaku, bekerja dan berfikir sebagai masyarakat digital (digital native).

Menurut Prensky seorang tokoh inovasi pendidikan menyatakan bahwa Digital native adalah generasi yang tumbuh dan dibesarkan di tengah dunia teknologi digital. Digital native adalah sebutan bagi generasi yang sedari lahir sudah terbiasa hidup dan dikelilingi oleh teknologi sebagai alat bantu dalam aktivitas kehidupannya sehari-hari (Chritina, 2016)

Arus perkembangan teknologi saat ini berkembang dengan pesat, jika dibandingkan dengan zaman dimana belum ada dan populernya media sosial, kebanyakan orang berkomunikasi dengan sms atau telepon lewat handphone, namun sekarang sejak adanya media sosial, mereka beralih dan cenderung berkomunikasi lewat layanan obrolan (chat) atau berkirim pesan lewat layanan yang tersedia di media sosial. Tidak terlepas juga dengan para digital native. Mereka sudah tak asing lagi dengan berbagai situs jejaring sosial tersebut. Sebut saja seperti Facebook, Instagram, Whatsapp, YouTube, LINE dan lain-lain.

Menurut Nasrullah (2015) Media sosial adalah medium di internet yang memungkinkan pengguna merepresentasikan dirinya maupun berinteraksi, bekerja sama, berbagi, berkomunikasi dengan pengguna lain, dan membentuk ikatan sosial secara virtual. Berdasarkan data reportal digital 2019, penggunaan media sosial di Indonesia mengalami peningkatan dari tahun sebelumnya. Berikut ini terdapat gambar yang menunjukkan jumlah pengguna media sosial di Indonesia tahun 2019:

\section{Gambar 1. Jumlah Pengguna Media Sosial di Indonesia Tahun 2019 (Januari)}

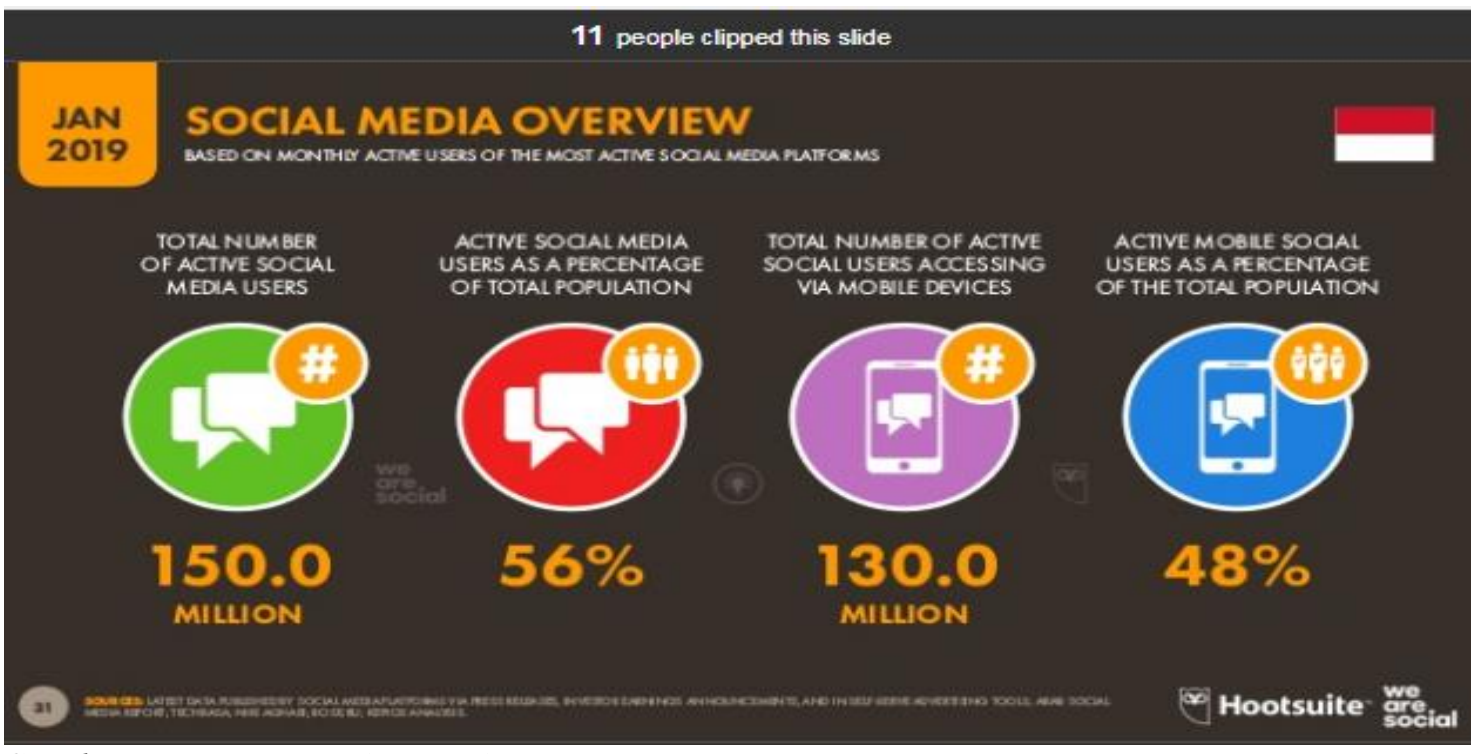

Sumber: Data Reportal Digital 2019 
Berdasarkan Gambar 1 diatas, ada sebanyak 150 juta pengguna aktif media sosial di Negara Indonesia dengan persentase 56\% di tahun 2019. Sedangkan pada tahun 2018, pengguna aktif media sosial mencapai 130 juta yang dipersentasekan sekitar 49\%. Hal ini menunjukkan adanya peningkatan dari tahun sebelumnya sebanyak $7 \%$ dalam setahun dengan pertambahan sekitar 20 juta pengguna aktif media sosial.

SMA Negeri 2 Painan merupakan salah satu sekolah menengah atas yang terletak di Kabupaten Pesisir Selatan. Sekolah ini berada di Jalan Perintis Kemerdekaan, Kecamatan IV Jurai Kabupaten Pesisir Selatan. Sekolah ini menerapkan kurikulum 2013. Suatu karakteristik yang dimiliki dari kurikulum 2013 adalah siswa dituntut lebih aktif di dalam proses pembelajaran. Penggunaan media sosial membawa dampak positif dan dampak negatif bagi siswa tersebut. Dampak positif penggunaan media sosial bagi siswa menurut Khoiratun antara lain: 1). Memperluas jaringan pertemanan, 2). Menambah wawasan sisiwa tentang berita atau kabar yang sedang banyak dibicarakan untuk bidang pendidikan, kebudayaan, dan lain-lain. 3). Sebagai sarana untuk berdiskusi mengenai pembelajaran (Rasyidah, 2017)

Disamping berdampak positif, penggunaan media sosial juga berdampak negatif terhadap siswa. Penggunaan yang tinggi dapat berdampak negatif bagi siswa yang Khoiratun yaitu : 1). Berkurangnya waktu belajar, terlalu lama bermain media sosial akan mengurangi jatah waktu belajar. 2). Mengganggu kesehatan, terlalu banyak menatap layar smartphone atau komputer ataupun laptop dapat mengganggu kesehatan mata. 3).Siswa menjadi mudah malas, tidak mengerjakan tugas karena selalu ingin tahu status temantemannya. Sehingga lebih banyak waktu yang terbuang sia-sia untuk hal yang kurang bermanfaat, contohnya chatting, yang akan berpengaruh terjadap minat belajar. 4). Kurangnya sosialisasi dengan lingkungan. Ini dampak terlalu sering dan terlalu lama bermain media social (Rasyidah, 2017). Hal ini cukup mengkhawatirkan perkembangan kehidupan sosial si anak. Mereka yang seharusnya belajar sosialisasi dengan lingkungan justru lebih banyak menghabiskan waktu di dunia maya.

Perkembangan teknologi digital saat ini bukan hanya memberikan kemudahan di dalam berkomunikasi tetapi juga memudahkan dalam pencarian informasi yang dibutuhkan. Melalui internet kita dapat mengakses sumber-sumber belajar digital yang saat ini dapat diakses dengan sangat cepat. Hal ini dibuktikan dengan adanya berbagai macam sumber belajar digital seperti e-book, e-journal, e-learning, digital library, video pembelajaran, YouTube, game pembelajaran, bahkan ada yang berbasis aplikasi seperti Ruangguru, Quipper, Zenius, dan lain-lain.

Menurut OECD kemajuan teknologi telah melahirkan sumber-sumber belajar baru. Digitalisasi menjadi karakter pembeda sumber-sumber tersebut (Camilleri,2016). Digital merujuk pada gabungan elemen perangkat keras (pemrosesan, memori, input, dan komunikasi) dan perangkat lunak (sistem operasi dan program aplikasi) untuk melakukan berbagai tugas. Dengan demikian sumber belajar digital dapat dipahami sebagai gabungan elemen perangkat keras dan perangkat lunak yang mempunyai potensi untuk mengatasi masalah belajar dan memfasilitasi kegiatan belajar (Christina, 2016).

Dengan perkembangan teknologi yang semakin maju, perlu adanya penggunaan teknologi yang dapat digunakan secara bijak terutama bagi siswa digital native di SMAN 2 Painan. Dalam penelitian ini, peneliti melihat bahwa tingkat penggunaan teknologi khususnya pada penggunaan media sosial dan sumber belajar digital. Untuk itu, peneliti tertarik untuk melakukan penelitian mengenai "Analisis penggunaan Media sosial dan Sumber belajar digital dalam pembelajaran bagi siswa digital native di SMAN 2 Painan". 


\section{METODE PENELITIAN}

Teknis analisis data yang digunakan dalam penelitian ini merupakan tipe deskriptif analisis survey. Menurut Fraenkel, Wallen \& Hyun (2012), a descriptive survey is a nonexperimental design which measures the characteristics of a sample at one point in time. Penelitian ini merupakan penelitian populasi yaitu penelitian yang melibatkan seluruh populasi (Nonprobability Sampling). Jumlah populasi dalam penelitian ini adalah 97 siswa digital native kelas XI di SMAN 2 Painan.

Menurut Sugiyono (2017) "Sampling jenuh adalah teknik penentuan sampel bila semua anggota populasi digunakan sebagai sampel. Istilah lain sampel jenuh adalah sensus, dimana semua anggota populasi dijadikan sampel. Dalam penelitian ini teknik pengukuran dilakukan dengan menghitung nilai Tingkat Capaian Responden (TCR) masing-masing kategori dari data deskriptif variabel. Rumus yang digunakan yaitu :

$$
\mathrm{TCR}=\frac{R s}{n} \times 100 \%
$$

Keterangan :

TCR = Tingkat Capaian Responden

Rs = Rata-rata skor jawaban responden

$\mathrm{n} \quad=$ Nilai Skor Jawaban

Kriteria Interpretasi skor untuk Tingkat Capaian Responden (TCR) adalah sebagai berikut.

Tabel 1. Kriteria Skala TCR

\begin{tabular}{lll}
\hline No. & Angka & Keterangan \\
\hline 1 & $00 \%-54 \%$ & Tidak baik ( Tidak Tinggi) \\
2 & $55 \%-64 \%$ & Kurang baik ( kurang Tinggi) \\
3 & $65 \%-79 \%$ & Cukup baik (cukup Tinggi) \\
4 & $80 \%-89 \%$ & Baik ( Tinggi) \\
5 & $90 \%-100 \%$ & Sangat baik (Sangat Tinggi) \\
\hline
\end{tabular}

Sumber: Sudjana dalam Syahron (2011)

\section{HASIL DAN PEMBAHASAN}

Dari penelitian yang peneliti lakukan pada siswa yang berjumlah 97 siswa kelas XI IPS SMAN 2 Painan terdiri dari rentangan tahun kelahiran 2002 sampai dengan 2004 yang diklasifikan ke dalam generasi digital native.

Grafik 1. Klasifikasi Responden Berdasarkan Tahun Kelahiran

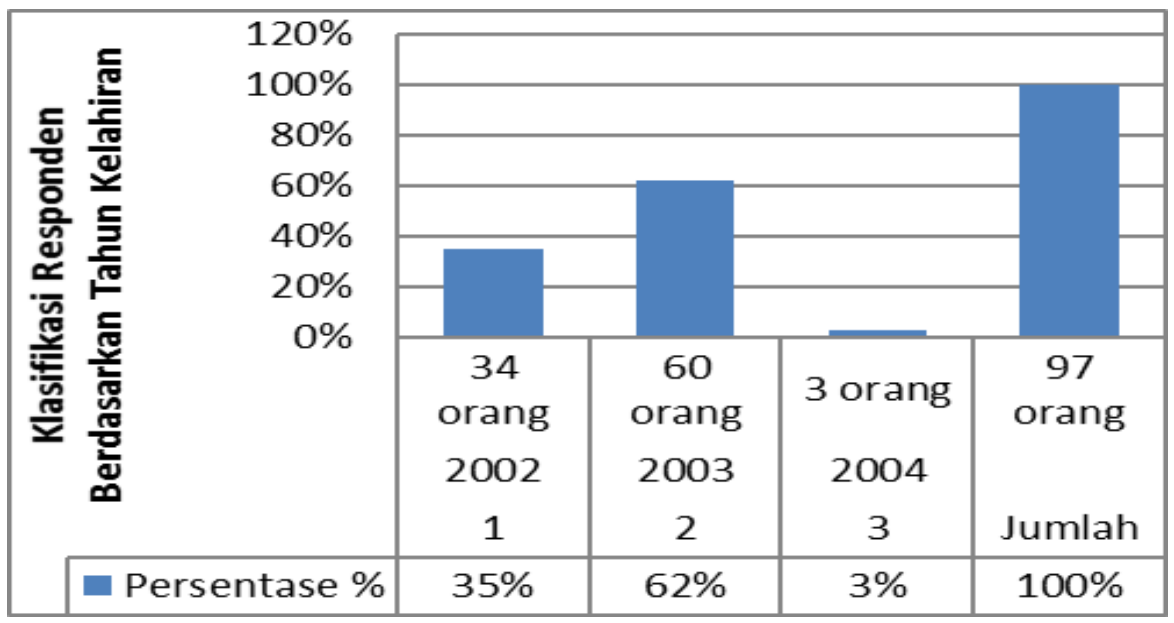

Sumber : Olahan Data Primer 2019 
Berdasarkan grafik 1 menunjukkan bahwa terdapat 97 siswa terdapat sebanyak 60 siswa dari tahun kelahiran 2003, 34 siswa dari tahun kelahiran 2002 dan Sisanya berasal dari kelahiran 2004 sebanyak 3 siswa. Hal ini menunjukkan bahwa responden terbanyak berasal dari tahun kelahiran tahun 2003 dan responden terkecil berasal dari kelahiran tahun 2004. Sedangkan klasifikasi responden berdasarkan jenis kelamin sebagai berikut.

Grafik 2. Klasifikasi Responden Berdasarkan Jenis Kelamin

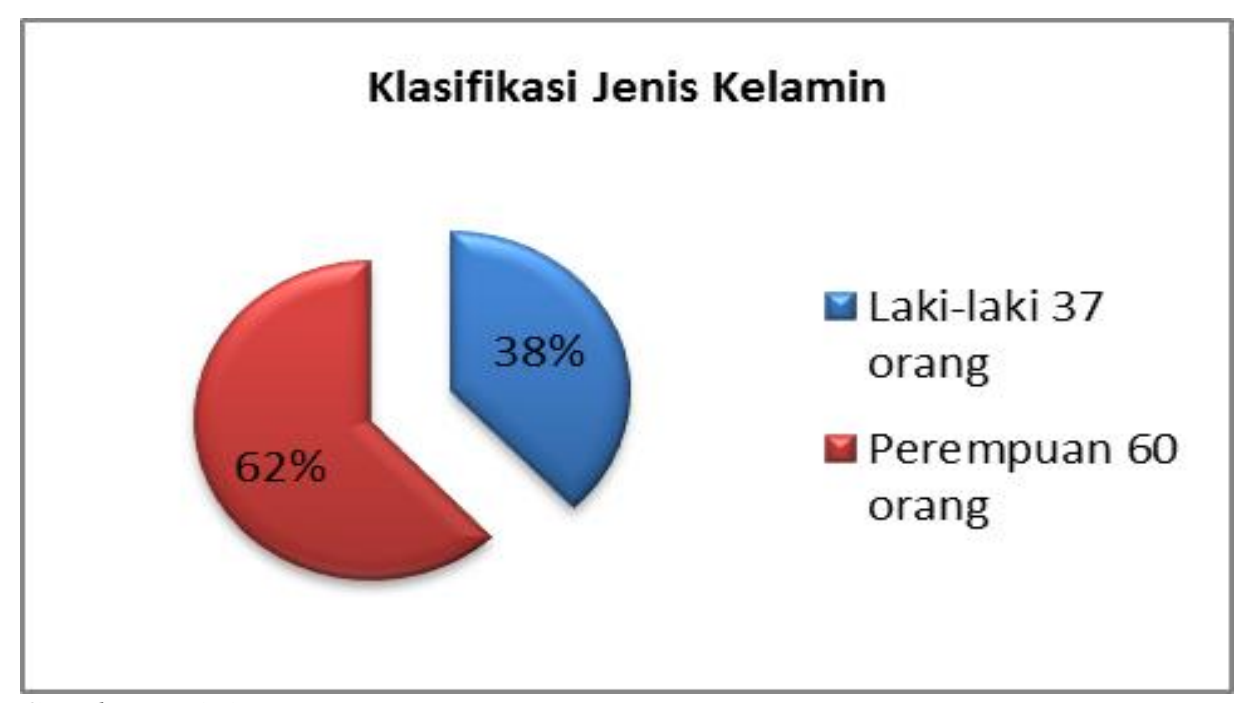

Sumber: Olahan Data Primer 2019

Berdasarkan grafik 2 dijelaskan bahwa sebanyak $62 \%$ responden merupakan perempuan dan 38\% merupakan laki-laki. Hal ini menunjukkan bahwa responden terbanyak merupakan berjenis kelamin perempuan. Penggunaan media sosial menurut Rasyidah (2017) memiliki empat indikator diantaranya alokasi waktu yang digunakan untuk mengakses media sosial, banyakya akun yang dimiliki, kegunaan media sosial dan dampak yang ditimbulkan dari penggunaan media sosial. Untuk mengetahui hasil penelitian tentang penggunaan media sosial pada digital native di SMAN 2 Painan, maka dari pengolahan data dilakukan deskripsi dengan tujuan menggambarkan propersi jawaban responden terhadap variabel penelitian.

Tabel 2. Distribusi Frekuensi Penggunaan Media Sosial Oleh Digital Native Kelas XI IPS Di SMAN 2 Painan

\begin{tabular}{lllll}
\hline No. & \multicolumn{1}{c}{ Indikator } & Mean & TCR $(\%)$ & Keterangan \\
\hline 1. $\quad \begin{array}{l}\text { Alokasi waktu mengakses media sosial } \\
\text { yang mereka miliki }\end{array}$ & $\mathbf{3 . 1 2}$ & $\mathbf{6 0 . 8 9}$ & Kurang tinggi \\
& $\begin{array}{l}\text { Banyaknya akun media sosial yang } \\
\text { dimiliki siswa }\end{array}$ & $\mathbf{4 . 2 7}$ & $\mathbf{8 5 . 3 6}$ & Tinggi \\
3. $\quad \begin{array}{l}\text { Kegunaan media social } \\
\text { 4. }\end{array}$ & $\mathbf{4 . 0 9}$ & $\mathbf{8 1 . 8 6}$ & Tinggi \\
$\quad \begin{array}{l}\text { mengakses media social } \\
\quad \text { Rata-rata }\end{array}$ & $\mathbf{2 . 7 6}$ & $\mathbf{5 5 . 2 1}$ & Kurang tinggi \\
\hline
\end{tabular}

Sumber : Olahan Data Primer 2019

5 | Jurnal Pendidikan Ekanami, Vol.13, No.I, 2020, Hal. I-7 
Berdasarkan Tabel 2 dapat dijelaskan bahwa penggunaan media sosial oleh digital native kelas XI IPS di SMAN 2 Painan cukup tinggi dengan rata-rata indikator sebesar 3,56 dan TCR 70,83\%. Penggunaan media sosial oleh digital native kelas XI IPS di SMAN 2 Painan yang cukup tinggi ini karena didasari adanya banyak akun media sosial yang dimiliki dengan rata-rata 4.27 dan TCR $85.36 \%$. Meskipun penggunaan media sosial belum memiliki dampak tinggi yang ditimbulkan dalam mengakses media sosial yang terlihat dari rata-rata indikator 2.76 dan TCR 55.21\%.

Hasil penelitian ini menunjukkan bahwa penggunaan media sosial cukup tinggi dengan rata-rata indikator sebesar 3,56 dan TCR 70,83\%. Hal ini mengindikasikan bahwa penggunaan media sosial memberikan dampak pembelajaran digital native di SMAN 2 Painan. Hal ini sejalan dengan pendapat Khoiratun menyatakan bahwa penggunaan media sosial memiliki dampak negatif kepada siswa diantaranya dapat mengurai waktu belajar siswa, membuat siswa menjadi malas dan sehingga nantinya akan berdampak kepada kurangnya motivasi belajar yang dimiliki siswa tersebut (Rasyidah, 2017). Hal ini sesuai dengan apa yang terjadi saat sekarang ini, faktanya tingkat penggunaan media sosial oleh siswa digital native cukup tinggi dapat dikatakan bahwa siwa mempunyai motivasi yang rendah dalam mengikuti pembelajaran di sekolah.

Sumber belajar digital menurut European Schoolnet (2012) memiliki beberapa indikator diantaranya dapat dilihat dari tabel sebagai berikut.

Tabel 3. Distribusi Frekuensi Sumber Belajar Digital Oleh Digital Native Kelas XI IPS Di SMAN 2 Painan

\begin{tabular}{ccccl}
\hline No. & Indikator & Mean & $\begin{array}{c}\text { TCR } \\
(\mathbf{\%})\end{array}$ & Keterangan \\
\hline 1. & $\begin{array}{c}\text { Penggunaan teknologi } \\
\text { (Hardware) }\end{array}$ & 3.59 & $71.75 \%$ & Cukup tinggi \\
2. & $\begin{array}{c}\text { Penggunaan aplikasi } \\
\text { (sorfware) }\end{array}$ & 3.25 & $65.07 \%$ & Cukup tinggi \\
3. & Pencarian informasi & 3.38 & $67.68 \%$ & Cukup tinggi \\
4. & $\begin{array}{c}\text { Penggunaan multimedia } \\
\text { dalam pembelajaran }\end{array}$ & 3.69 & $73.87 \%$ & Cukup tinggi \\
& $\quad$ Rata-rata & $\mathbf{3 . 4 8}$ & $\mathbf{6 9 . 5 9}$ & Cukup tinggi \\
\hline
\end{tabular}

Sumber : Olahan Data Primer 2019

Berdasarkan tabel 3 memperlihatkan bahwa tingkat penggunaan sumber belajar digital oleh digital native kelas XI IPS di SMAN 2 Painan tinggi dengan rata-rata 3.48 dan TCR 69.59\%. Penggunaan sumber belajar digital yang tinggi tersebut terbentuk karena adanya penggunaan multimedia dalam pembelajaran dengan rata-rata 3.69 dan TCR 73.87\%. Hal ini juga didukung dengan penggunaan teknologi (hardware) seperti laptop ataupun komputer dengan nilai rata-rata 3.59 dan TCR $71.75 \%$. Sumber belajar digital digunakan oleh digital native kelas IPS di SMAN 2 Painan untuk mencari informasi seputar pembelajaran hal ini terlihat dari rata-rata 3,38 dan TCR 67,68\%. Namun penggunaan aplikasi pembelajaran (software) sebagai sumber belajar digital masih kurang dilihat dari nilai rata-rata 3.05 dan TCR $65.07 \%$. Artinya digital native kelas XI IPS di SMAN 2 Painan belum sepenuhnya menggunakan aplikasi pembelajaran (software) sebagai sumber belajar digital.

Hal ini mengindikasikan bahwa sumber belajar digital memberikan dampak dalam pembelajaran bagi siswa digital native di SMAN 2 Painan. Dapat diartikan bahwa tinggi rendahnya sumber belajar digital akan menentukan tinggi rendahnya hasil belajar digital native tersebut. Semakin tinggi sumber belajar digital maka akan semakin tinggi pula hasil 
belajar digital native tersebut, begitu pun sebaliknya rendah sumber belajar digital maka akan semakin rendah pula hasil belajar digital native tersebut.

\section{KESIMPULAN}

Berdasarkan hasil penelitian dan pembahasan tentang penggunaan media sosial dapat disimpulkan bahwa penggunaan media sosial oleh siswa digital native di SMAN 2 Painan dapat digolongkan cukup tinggi. Berarti dapat dikatakan penggunaan media sosial memiliki pengaruh negatif dalam pembelajaran jika digunakan secara terus menerus oleh siswa digital native. Untuk itu perlu adanya pengarahan dan pengawasan oleh orang tua dan guru di sekolah terhadap penggunaan media sosial oleh siswa digital native agar tidak dampak negatif dapat dikurangi.

Sedangkan berdasarkan hasil penelitian dan pembahasan sumber belajar digital oleh siswa digital native dapat disimpulkan bahwa penggunaan sumber belajar digital dapat digolongkan cukup tinggi. Artinya sumber belajar digital memiliki dampak yang positif jika digunakan secara terus menerus dalam pembelajaran. Oleh karena itu, sumber belajar digital perlu dimanfaatkan semaksimal mungkin untuk meningkatkan hasil belajar siswa selain itu juga dapat menambah wawasan siswa digital native dalam pembelajaran.

\section{REFERENSI}

Camilleri, MA, dkk (2016) Digital Learning Resources and Ubiquitous Technologies In Education. University of Malta: Springer Science and Business Media Dordrecht, p. 1-18: [https://www.um.edu.mt/library/oar//handle/123456789/10850]

Chritina, F. d. (2016). Persepsi Guru Tentang Digital Natives, Sumber Belajar Digital dan Motivasi Memanfaatkan Sumber Belajar Digital. Jurnal Inovasi Teknologi Pendidikan, 13-24.

E-Safety Label: European ScoolNet (2012). What is the eSafety Label?

http://www.esafetylabel.ue/web/guest/about

Jack R. F, Norman E.W, Helen H. H (2012). How to Design and Evaluate Research in Education. McGraw-Hill Higher Education.

Nasrullah, R (2015) Media Sosial Prespektif Komunikasi, Budaya, dan Sosioteknologi. Bandung: Simbiosa Rekatama Media

Rasyidah, DS (2017) Pengaruh Penggunaan Media Sosial dan Jenis-jenis Media Sosial terhadap Intensitas Belajar PAI Siswa Kelas VIII DI SMP N 3 Karangdowo Klaten Tahun Pelajaran 2016/2017. Jurnal Skripsi tidak diterbitkan. Yogyakarta: Fakultas Ilmu Tarbiyah dan Keguruan.

Simon Kemp, dkk (2019) Data reportal, diakses pada 1 Juli 2019 pukul 09.30 WIB, [https://datareportal.com/]

Sugiyono (2017) Metode Penelitian Kuantitatif, kualitatif, dan Kombinasi (Mixed Methods). Bandung. Alfabeta.

Sudjana, N. (2005). penilaian hasil proses belajar mengajar. bandung: PT. Remaja rosdikarya. 